\title{
Multi-Media Instructional Package as a Motivating and Innovative Tool for Improving the Teaching and Learning of Yoruba Language and Culture among Osun State Junior Secondary School Students
}

\author{
Boboye Florence Toyin \\ Sofowora Olaniyi Alaba (Ph.D) \\ Obafemi Awolowo Uninersity ,Ile-Ife, Faculty of Education \\ Dept of Educational Technology lle-Ife, Osun State, Nigeria \\ oasofowora@yahoo.com/ oasofowora@oauife.edu.ng
}

Doi:10.5901/ajis.2014.v3n4p179

\begin{abstract}
The sudden neglect of Yoruba Language and culture have been a major concern for the Egbe Akomolede Yoruba(Yobuba Language Scholars Teachers and researchers). They raised their fear that if no concerted is made, the Language may soon face extinction. The group identified several factors like globalization and the advent of the emerging technologies that have made a devastating impact on the Language. The low enrolment of students and lack of interest of students to pursue further studies in the subject coupled with shortage of qualified teachers are factors militating against the teaching and learning of the subject. Parental attitude at discouraging their wards from speaking the Language at home is another major problem. The resultant effect is that majority of today's youths can not speak Yoruba language fluently. In spite of the fact that the Language was made compulsory at the junior secondary school level students performance in examinations were still very poor. In response to the call by Egbe Akomolede Yoruba and Ngugi, an intervention must be made to correct the situation. Hence, the main focus of this study is to investigate how student's interest and performance in the Language could be enhanced using multi media leaning package. The study adopted the pretest, post test control group experimental design. The sample was one hundred junior secondary school students selected from two schools using purposive and simple random sampling techniques. these were also randomly assigned to two groups(experimental and control groups). Three research instruments were used for data collection. The instruments were validated for content validity and opinion of experts sought. Reliability was measured using test re- test method. Data collected were analyzed using descriptive and inferential statics of t-test. The results showed that multi media learning approach was a better and preferred approach to the conventional approach .It enhanced better performance than the conventional method.
\end{abstract}

Keywords: Globalization, disruptive innovation, emerging technologies, learning styles language and culture

\section{Background}

The effect of globalization and the emerging technologies are numerous; it is felt on every sphere of human endeavour. Hence, language and culture are non separable from its impact and development. In fact modern schools of thought opine that the impact of globalization and technologies have caused a disruption, hence the acronym Disruptive Innovation. It is argued that the disruption caused have led to the sudden neglect of Yoruba culture and Language. Further observation shows that majority of the children today cannot speak or write correctly Yoruba Language. A critical examination of the conversation of the youths today reflects code switching and mixing. It is therefore disheartening that we are gradually loosing our language.

Fabunmi and Salawu (2005) identify other factors different from the above, they termed it parental factors. These schools of thought argued that most parents derogatorily termed Yoruba as a Vernacular which is prohibited in many elite homes and in some schools. Hence, in these homes English Language is the medium of communication. It is also a reflection of social class. Any child or student seen speaking Yoruba in the public is therefore regarded as not well to do or the poor. The schools are also partly to blame for the poor state of development of Yoruba Language. As most schools do not faithfully implement the sub-section of the National Policy on Education that made the teaching and learning of indigenous language compulsory at the junior secondary school level. Complicating the situation the more is the fact that there are shortage of qualified Yoruba Language teachers to teach the students in schools. Many are not interested in going to the universities to study Yoruba Language because of lack of employment and government attitude. This 
development has in no doubt affected the development of the language negatively making the professionals Egbe Akomolede Yoruba to cry out. In 1992,Krauss corroborated the fear of the Egbe Akomolede Yoruba when he said that Yoruba Language is nearing extinction. It is therefore not surprising to witness downward enrolment, poor students performance and lack of motivation among students. At the primary school level the situation is not better, many of the pupils can not recognize and pronounce Yoruba alphabets let alone read Yoruba sentences correctly.

\section{Review of Related Literature}

Relevant studies and research endeavour at improving language education in recent years are shifting emphasis from the language teaching methodology to language learners and factors that influence language learning. According to Richards \& Rodgers (2001) modern day language teaching no longer consider teaching methods to be the most important factor in determining the success or failure of language teaching and learning. To this school of thought learners shape their own learning process. Hence, they opine that individual differences and learning styles is the panacea to improving language learning. It was therefore suggested that more and more researches should be conducted to handle individual differences in the learning process . Among those that advocated for this are: Bialystok (1979); Chapelle \& Roberts (1986); Roth (2005).

The main thrust of the above studies are to provide empirical answers to the fundamental questions as to what makes a good language learner and why some students develop proficiency more quickly and easily than others do. One of the causes is that there are considerable individual differences in language learning in terms of gender, age, social status, motivation, attitude, aptitude, and culture. These schools of thought also argued that what works for one learner might not work for another. Thus students take in and comprehend information in different manners. Some prefer to learn individually whereas others prefer to interact with their peers. In addition, it was observed that some enjoy listening to lectures while others like to do more experiments. Hence the relevance of the following theories like Kolb, 1984; Reid, 1987; Celce-Murcia, 2001 are that they reveal the different ways how learners take in and processes information known as learning styles or learning preferences. Researchers and language teachers in several countries have discussed a great deal on the topics of learners' characteristic and individual differences in learning English. Relevant variables such as gender, age, language experience, or English proficiency to accommodate different learners and language learning styles have been one of the most popular aspects researchers have focused on; little attention was paid to Yoruba Language. Some researchers such as Nguyen (1989), Dao (1982), and Le (1982) in their studies referred to learning strategies in general. Le (1999) studied the differences in language learning strategies of learners of English in Hue City and Nguyen (2005) investigated the different reading style preferences of the ESP students at Ton Duc Thang University. In other words, the perception and learning style preference in language learning has been ignored in the learning process. Majority of the teachers are unaware of their students' learning styles. They are also unaware of the importance to identify learning styles. Thus, there is a need to assess the learning styles of the students as well as other. In the Nigerian classrooms that are usually characterized by large classroom enrolment, the issue of individual learners learning style preference is not usually considered. Most method of teaching is through the traditional method (teacher center). In language learning you can draw a basic distinction between students who are reflective and cautious, and so tend to remain within the task you set for them, and students who are impulsive and more prepared to take risks, to experiment with language, and so are more likely to go beyond the task set for them. You can identify people who are, or tend to be rather anxious, and thus are less tolerant of ambiguity, and people who tend to be relaxed, which allows them to tolerate ambiguity better. On one side, you may find people who tend to be inhibited, introverted, and perhaps a bit rigid; on the other side, people who tend to be uninhibited, extroverted, and maybe a bit more flexible.

Reflective learners learn more effectively when they have time to consider options before responding whereas impulsive learners are able to respond immediately and take risks.

Scarcella (1990) portrays that visual students like to read and obtain a great deal from visual stimulation. For them, lectures, conversations, and oral directions without any visual backup can be confusing. Visual learners will be able to recall what they see and will prefer written instructions. These students are sight readers who enjoy reading silently. They will learn by observing and enjoy working with computer graphic, maps, graphs, charts, diagrams, or text with a lot of pictures (p. 320).

In contrast, auditory students are comfortable without visual input and thus enjoy and profit from unembellished lectures, conversations, and oral directions. They are excited by classroom interactions in role-plays and analogous activities. Students with this style will be able to recall what they hear and will prefer oral instructions. They can recreate what they hear by concentrating on previous lessons. These students should be introduced to new information by hearing 
it (Carbo, Dunn, and Dunn, 1986). They learn by listening and speaking. These students enjoy talking and interviewing. They are phonetic readers who enjoy oral reading, choral reading, and listening to recorded books. They learn best by interviewing, debating, giving oral reports, or participating in oral discussions of written material. According to Aduwa and lyamu (2008) some of the above challenges can be overcome. The use of multimedia in teaching and learning Yoruba Language is advocated. The two schools of thought also share the opinion that its usage will bring change in teaching from teacher direct teaching to self directed/learners centered learning approach. According to Kearslley (2000) multimedia learning also enhances interactive learning. It is believed that interactivity encourages discovery and learner to go at their own pace rather than teacher directed learning. Other features of multi-media learning that motivates the students to learn are ability to integrate graphics, animation and video. This scholar therefore belief that the flexibility of multimedia to accommodate different stimuli is one of the possible reasons for engaging more students to learn .Reeves (1998) also share the opinion that multi-media learning stimulates more than one sense at a time and in doing this, it is attention getting and holding. It is therefore the opinion of these schools of thought that multi-media technique is more useful for teaching languages than the traditional approach. This is because it takes into consideration the different learning strategies .Anderson and Pearson (2004) are of the view that multi-media can also promote transcultural communication and cultural awareness.. The two came up with schema theory, that what a learner has in his /her memory affects the reading and comprehension. Hence, they agreed that learner's background knowledge and culture plays prominent role in the comprehension of a text. In Yoruba Language, the situation is not different. Most text materials are usually about persons, events, customs, culture, history, religion or politics of Yoruba people. Ability to read fluently therefore depend not only on the readers language proficiency but also on his/her mastery of the background knowledge. Thus, it is general axiom that a good background knowledge in reading suggests ability to overcome linguistic deficiencies. Hence, these groups of thought opine that multi -media technologies provide more suitable opportunity for students to build background knowledge on relent topics prior to reading through appropriate pre-reading activities. They also opine that by using multi media technologies, students develop relevant schema and cultural knowledge. A good example, is for a teacher to present a soft ware package on Yoruba Land with simulation, video dramatized documentaries and idiomatic background information on the Yoruba's. It will stimulate learning and expand their knowledge of inter-cultural communicative ability .Consequently; the students will develop language awareness and culture.

It is in view of the important roles that multi-media technology plays that the researchers decided to investigate how the attitude and performance of students of Yoruba Language can be improved . In addition, the study will provide information on how the students can recognize and pronounce Yoruba alphabets and also to read Yoruba sentences correctly and fluently. The motivating factor for the use of multi-media learning package at the secondary schools is based on the fact that it has been successfully used by the Japanese and Chinese to teach their own Languages. The main thrust of this study therefore is to investigate the effectiveness of multi- media in learning Yoruba Language. Hence the following specific objectives are stated.

\section{Specific Objectives of the Research:}

The specific objectives of the study are to:

(i) design and develop a Multimedia Instructional Learning Package for Learning Yoruba Language among Nursery pupils in lle-Ife;

(ii) find out the perception of the students about the effectiveness of multi media in learning Yoruba Language in junior secondary schools in lle-Ife Osun State;

(iii) determine the effectiveness of the Multi-media Learning Package in improving the spelling skill of junior secondary school students in Yoruba Language, and

(iv) examine whether the Multimedia Instructional Learning Package can effectively enhance students attitude to learning Yoruba Language

\section{Research Methodology}

The study adopts the pretest, post test control group experimental design. 


\subsection{Population and Sample}

The population for the study consists all the junior secondary school students in Ife Education Area that registered for Yoruba Language as one of the subjects in the school curriculum. From where two secondary schools were purposely selected based on availability of the subject, qualified Yoruba Language teachers, electricity and ICT facilities .One hundred students were selected from the two schools, making fifty from each school. They were also assigned to two groups (experimental and control) using simple random sampling technique.

\subsection{Research Instrument}

Three research instruments (i) The Multi-media interactive learning package designed locally by the researchers using power point version 10 that allows for animation, audio, text and instructional movie. The designed package contained topics like ìró alifabẹẹti Yorùbá (Aa-Yy), kónsónantì Yorùbá, fáweeli Yorùbá , ìsẹda ọrọ Yorùbá ati ayoka Yoruba based on the junior secondary school syllabus. Included in the package is opportunity to record the student's voice. The second is the Yoruba Language Achievement Test (YOLATE) containing 20 multiple test items to measure the student's spelling, pronunciation and comprehension skills. The test items were also based on accuracy, Word Correct Per Minutes (WCPM), rate at which each words were pronounced and prosody. The spelling aspect comprised reading words aloud as part of a sentence which students are expected to recognize and write down correctly. On reading and pronunciation, each of their reading was recorded through a recording device. After completion of the exercise, each of their script and recorded tapes were graded and recorded as raw-scores. The last instrument was the attitude inventory questionnaire. It was designed to measure student's attitude toward Yoruba Language.

\subsection{Validation/Reliability of Instruments}

In order to validate the instruments used, content validity and a pilot test were carried out. The package was shown to group of experts in Educational Technology, Tests and measurement and Yoruba Teachers in the Schools for their comments on the ability of the instruments to measure what it was designed to measure. Based on their comments modification was made. The package was then pilot tested on twenty students that were not part of the sample to be used. Another test was conducted after two weeks on the same sample. A reliability index of $0.76,0.85$ and 0.78 were gotten

\subsection{Treatment}

The package was used individually by the participants in the experimental group and the experiment lasted six weeks. First week was used for pre-test and introduction to the use multi-media package for learning. While the second to the forth week was used for teaching in the two groups. The 50 students in the experimental group were exposed to the multi-media package while the control group (50 students) was taught the same content using the conventional method. The post-test was administered during the sixth week. Data collected was analyzed using descriptive and inferential statistics of simple percentage, mean standard deviation and t- test.

\section{Results and Discussions}

Student's perception about the effectiveness of multimedia package

\begin{tabular}{|c|l|c|c|c|c|c|}
\hline S/N & \multicolumn{1}{|c|}{ SA } & A & UND & SD & D \\
\hline 1 & $\begin{array}{l}\text { Multimedia package is an effective tool for teaching Yoruba language at the } \\
\text { junior secondary schools }\end{array}$ & $\begin{array}{c}22 \\
(42 \%)\end{array}$ & $\begin{array}{c}16 \\
(32 \%)\end{array}$ & 0 & $\begin{array}{c}2 \\
(4 \%)\end{array}$ & $\begin{array}{c}10 \\
(20 \%)\end{array}$ \\
\hline 2 & Multimedia package is very easy to use & $\begin{array}{c}14 \\
(28 \%)\end{array}$ & $\begin{array}{c}24 \\
(48 \%)\end{array}$ & 0 & $\begin{array}{c}7 \\
(14 \%)\end{array}$ & $\begin{array}{c}5 \\
1(0 \%)\end{array}$ \\
\hline 3 & Multimedia instruction in Yoruba is very interesting & $\begin{array}{c}25 \\
(50 \%)\end{array}$ & $\begin{array}{c}15 \\
(30 \%)\end{array}$ & 0 & $\begin{array}{c}3 \\
(6 \%)\end{array}$ & $\begin{array}{c}7 \\
(14 \%)\end{array}$ \\
\hline 4 & $\begin{array}{l}\text { Leaning Yoruba using multimedia package is better than the convectional } \\
\text { method }\end{array}$ & $\begin{array}{c}20 \\
(40 \%)\end{array}$ & $\begin{array}{c}15 \\
(30 \%)\end{array}$ & $\begin{array}{c}8 \\
(16 \%)\end{array}$ & $\begin{array}{c}7 \\
(14 \%)\end{array}$ \\
\hline 5 & Multimedia package makes spellings easier and learning clearer & $\begin{array}{c}18 \\
(36 \%)\end{array}$ & $\begin{array}{c}15 \\
(30 \%)\end{array}$ & $\begin{array}{c}8 \\
(16 \%)\end{array}$ & $(18 \%)$ \\
\hline
\end{tabular}




\begin{tabular}{|c|l|c|c|c|c|c|}
\hline 6 & Multimedia instruction enhances the correct pronunciation of Yoruba words & $\begin{array}{c}23 \\
(46 \%)\end{array}$ & $\begin{array}{c}13 \\
(26 \%)\end{array}$ & $\begin{array}{c}4 \\
(8 \%)\end{array}$ & $\begin{array}{c}10 \\
(26 \%)\end{array}$ \\
\hline 7 & lam motivated to learn Yoruba language through multimedia & $\begin{array}{c}18 \\
(36 \%)\end{array}$ & $\begin{array}{c}17 \\
(34 \%)\end{array}$ & $\begin{array}{c}11 \\
(22 \%)\end{array}$ & $\begin{array}{c}4 \\
(8 \%)\end{array}$ \\
\hline 8 & $\begin{array}{l}\text { Multimedia instructional package enhances collaborative work among } \\
\text { students }\end{array}$ & $\begin{array}{c}21 \\
(41 \%)\end{array}$ & $\begin{array}{c}19 \\
(38 \%)\end{array}$ & $\begin{array}{c}8 \\
(16 \%)\end{array}$ & $\begin{array}{c}2 \\
(4 \%)\end{array}$ \\
\hline \multirow{2}{*}{9} & Multimedia package enhances creativity and interpersonal communication & $\begin{array}{c}14 \\
(28 \%)\end{array}$ & $\begin{array}{c}23 \\
(46 \%)\end{array}$ & $\begin{array}{c}2 \\
(4 \%)\end{array}$ & $\begin{array}{c}11 \\
(22 \%)\end{array}$ \\
\hline 10 & Multimedia in Yoruba language encourages self-paced learning & $\begin{array}{c}13 \\
(26 \%)\end{array}$ & $\begin{array}{c}18 \\
(36 \%)\end{array}$ & $\begin{array}{c}12 \\
(24 \%)\end{array}$ & $\begin{array}{c}7 \\
(14 \%\}\end{array}$ \\
\hline 11 & $\begin{array}{l}\text { lefore the introduction of multimedia in our class, Yoruba lessons are } \\
\text { always dull and uninteresting }\end{array}$ & $\begin{array}{c}15 \\
(30 \%)\end{array}$ & $\begin{array}{c}20 \\
(40 \%)\end{array}$ & $\begin{array}{c}6 \\
(12 \%)\end{array}$ & $\begin{array}{c}9 \\
(18 \%)\end{array}$ \\
\hline 12 & $\begin{array}{l}\text { lenjoyed my Yoruba lesson through multi-media instruction than the } \\
\text { conventional method }\end{array}$ & $\begin{array}{c}18 \\
(36 \%)\end{array}$ & $\begin{array}{c}26 \\
(52 \%)\end{array}$ & $\begin{array}{c}4 \\
(8 \%)\end{array}$ & $\begin{array}{c}2 \\
(4 \%)\end{array}$ \\
\hline
\end{tabular}

Based on the data analyzed, it was observed that $42 \%$ of the respondents strongly believe that multi media was effective in learning Yoruba while $32 \%$ believed strongly and only $26 \%$ hold a contrary opinion. This was further corroborated by the ratings of the students (72\%) who said Multimedia in Yoruba language provides opportunity for creative self expression and interpersonal communication. In addition to the above, $70 \%$ of the respondents were of the opinion that before introducing multi media method, their classroom is always dull and uninteresting. In conclusion, $88 \%$ of the respondents shared the opinion that they preferred the multi media method to the conventional method. In order to check the results further, a more robust statistics was carried out. A t- test was carried out on students in the two groups ( i.e the experimental and control groups).Find the results obtained on table 2

Table 2. t-Test of the Students Exposed to the Multi-media Instructional Package and those Exposed to the Conventional Group

\begin{tabular}{|c|c|c|c|c|c|c|c|}
\hline Test & Group & $\mathrm{N}$ & Mean & Std. Deviation & $\mathrm{t}$ & $\mathrm{df}$ & Sig. \\
\hline \multirow{2}{*}{ Pre Test } & Experimental & 50 & 2.400 & .90351 & \multirow{2}{*}{0.821} & \multirow{2}{*}{98} & \multirow{2}{*}{0.05} \\
\cline { 2 - 5 } & Control & 50 & 2.2400 & 1.04119 & \multirow{2}{*}{$* 10.733$} & \multirow{2}{*}{98} & \multirow{2}{*}{0.05} \\
\hline \multirow{2}{*}{ Post Test } & Experimental & 50 & 2.6600 & .84781 & & \\
\cline { 2 - 5 } & Control & 50 & 5.2000 & 1.44279 & &
\end{tabular}

From Table 2 the results showed that at the pre test there was no significant difference in the spelling and reading skills of the two groups. The $t$ value of 0.821 revealed that it was not significant. It therefore implied that the two groups had the same entry behaviour. At the post test there were remarkable difference in the mean values and standard deviations (5.2000 and 2.666).When this was subjected to $t$ test, the t-value of -10.733 was obtained, which was significant at 0.05 . It implied that the intervention programme had a significant impact on the spelling and reading skills of students who were exposed to multimedia instructional package, Thus it can be concluded that the package was responsible for the enhanced performance of students, hence it was effective in improving spelling, pronunciation and reading skills of the students.

With respect to its ability to motivate the students to learn and appreciate their language and culture, find the results in table 3

Table 3: Effect of the Multimedia Instructional Package on student's Attitude towards Yoruba Language

\begin{tabular}{|c|c|c|c|c|c|c|c|}
\hline Test & Group & $\mathrm{N}$ & Mean & Std. Deviation & $t$ & $\mathrm{df}$ & Sig. \\
\hline \multirow{2}{*}{ Pre Test } & Experimental & 50 & 2.5200 & 1.11098 & \multirow{2}{*}{1.480} & \multirow{2}{*}{98} & \multirow{2}{*}{0.05} \\
\hline & Control & 50 & 2.2000 & 1.04978 & & & \\
\hline \multirow{2}{*}{ Post Test } & control & 50 & 2.8200 & .87342 & \multirow{2}{*}{-12.562} & \multirow{2}{*}{98} & \multirow{2}{*}{0.05} \\
\hline & Experimental & 50 & 5.4800 & 1.21622 & & & \\
\hline
\end{tabular}

Table 3 presents the attitude of the students at pre and post tests to Yoruba Language. The results obtained at the pre 
test indicated that there was no significant difference in the attitude of the respondents at the pre-test. However, after exposing the respondents to the multi media instructional package there was a significant improvement in the attitude of the students that were exposed to the package compared to the conventional method. The t-value obtained from the analysis is -12.562 , which was significant at 0.05 level . It therefore suffice to say that the intervention programme enhanced students positive attitude to learn Yoruba .Corroborating the result is the students ratings on table 1 items 7-12. When $70 \%$ of the participants said they were motivated to learn Yoruba Language. Like wise $70 \%$ said the introduction of multi media package in teaching and learning Yoruba was better and more creative approach. In summary, 88\% opined that they preferred the multi media approach to the conventional method of teaching Yoruba Language. Based on the above findings and the t-test, the null hypothesis that says that the use of multi media instructional package does not necessarily influence student's attitude to learning Yoruba Language was rejected

\section{Summary and Conclusions}

Based on the findings of this study, it was concluded that Multimedia Instructional Package is best suited for learning Yoruba spelling, reading and comprehension skills. The use of Multimedia Instructional Package to teach Yoruba language produced a significant improvement in the spellings, reading skills and interest of students in Yoruba language.

\section{Recommendations}

Yoruba teachers must take the advantages of modern technologies in teaching and learning. In this respect they need to acquire competency and the required ICT skills. Constant workshop and re-training programmes should be carried out on modern methods of teaching and procedure for developing and production of multimedia Packages. The use of Multimedia Instructional Package for teaching Yoruba language should be encouraged by the government and the Ministry of Education. Modern and relevant text books on Yoruba Languages should be made available for the students. These text materials should be technically good and within the reach of the students. They must also be user friendly and motivating. Each secondary school should have an Educational Technology Center where teachers and students could get modern Instructional Package and multimedia packages for integration into teaching and learning.

Parents should encourage their children to study Yoruba languages at and beyond the secondary school level.

\section{References}

Anderson, J.A., and Adams, M. (1992). Acknowledging the learning styles of diverse student populations: implications for instructional design. In: Teaching for Diversity: New Directions for Teaching and Learning, vol. 49,

Arohunmolase, O. (2000). Introducing Hausa, Igbo, and Yoruba as Second Languages In Primary school Curriculum. In Akindehin, O. and Adeboyeje, Reuben, A. (eds.), Challenges of the third millennium for primary education in Nigeria, Readings in Nigeria, readings and research in schooling. Akure: Onward Printers.

Bialystok, E. (1979). A theoretical model of second language learning. Language Learning, 69-83.

Bialystok, E., 1990: Communication strategies: A psychological analysis of second-language use. Oxford, U.K.: Blackwell.

Carbo, M., Dunn, R., \& Dunn, K. (1986). Teaching students to read through their individual learning styles. Englewood Cliffs, NJ: Prentice-Hall.

Celce-Murcia, M. (Ed.). (2001). Teaching English as a second or foreign language (3rd ed.). Boston, MA: Heinlein \& Heine.

Chapelle, C. \& Roberts, C. (1986). Ambiguity tolerance and field independence as predictors of proficiency inEnglish as a second language. Language Learning, 27-45.

Dao, V.T.. (1982). Rationalize the ways of thinking, working, and learning. Hanoi: Youth Press.

Fabunmi, F.A and Salawu, A.S. (2005) Is Yorùbá an Endangered Language?_Nordic Journal of African Studies 14(3): 391-408 Retrieved from http://www.njas.helsinki.fi/pdf-files/vol14num3/fabunmi.pdf

Kolb, D.A. (1984). Experiential learning: Experience as the source of learning and development. Englewood Cliffs, NJ: Prentice-Hall.

Le, H.C.. (1982). Teaching and learning methods in Mathematics high school. In Proceedings of the First National Conference of Pedagogy: Some results and research into pedagogy. Hanoi, Institute of Educational Sciences.

Le, T.H. (1999). Research into language learning strategies of different groups of learners in Hue City. Website of Proceedings.

Nguyen, N.Q. (1989). General Teaching Theories, Volume 1. Central Education Management School.

Nguyen, T.T. (2005). Reading Style Preferences of the ESP Students at Ton Duc Thang University. ERC of HCM University of Social Sciences \& Humanities.

Reese, V.L. (2005). Learning-style preferences of diverse freshmen populations in a large private metropolitan university by gender, grade-point average, and institution. (Doctoral dissertation, St. John's University.

International, 66(09). (UMI No. 3187931)

Reid, M.J. (1987). The learning style preferences of ESL students. TESOL Quarterly. 21(1): 87-111.

Richards, J. C. \& Rodgers, T. S. (1986) Approaches and Methods in language teaching: A Descriptions and Analysis. New York: Cambridge University Press

Roth, P(2005) Dramatic lesson on relationship take center stage. Herald December,4.Miami

Rossner, Richard. (1988). Materials for communicative language teaching and learning. Annual Review of Applied Linguistics, 8, 140-163. 